Universidade Tecnológica Federal do Paraná - UTFPR

Campus Ponta Grossa - Paraná - Brasil

ISSN: 1981-3686/v. 04, n. 01, p. 91-99, 2010

D.O.I: $10.3895 / \mathrm{S} 1981-36862010000100010$
Revista Brasileira deTecnologia

Agroindustrial

\title{
CARACTERIZAÇÃO FÍSICO-QUÍMICA DA FARINHA DE MANDIOCA DO GRUPO D’ÁGUA COMERCIALIZADA NA CIDADE DE BELÉM, PARÁ
}

\section{PHYSICOCHEMICAL CHARACTERIZATION OF CASSAVA FLOUR FROM WATER GROUP TRADED IN THE CITY OF BELÉM, PA}

\author{
Renan Campos Chisté ${ }^{1}$; Kelly de Oliveira Cohen ${ }^{2}$ \\ ${ }^{1}$ Universidade Estadual de Campinas - UNICAMP - Campinas-SP - Brasil renanchiste@gmail.com \\ ${ }^{2}$ Embrapa Cerrados - Planaltina-DF - Brasil - kelly.cohen@cpac.embrapa.br
}

\begin{abstract}
Resumo
O objetivo deste trabalho foi realizar a análise físico-química nas farinhas de mandioca do grupo d'água, subgrupo fina, tipo 1, comercializadas na cidade de Belém,PA. Para umidade, todas as amostras encontram-se dentro dos padrões exigidos pela legislação que é de 13\%. O teor de cinzas encontrado foi de 0,16 a 0,94\%, estando apenas uma amostra acima do máximo permitido pela legislação, que é de 1,5\%. Com relação à acidez total, nove amostras encontravam-se acima do valor exigido pela legislação (3 meq $\mathrm{NaOH} / \mathrm{lOOg}$ ) e apenas uma apresentava acidez dentro do aceitável. Para o amido, todas as amostras estavam abaixo do mínimo exigido pela legislação, que é de 70\%. Com relação a proteínas e lipídios, os percentuais obtidos foram de 0,58 a 1,38\% e 0,30 a 1,02\%, respectivamente. A atividade de água ficou na faixa de 0,18 a 0,51, sendo considerado um produto microbiológicamente estável.
\end{abstract}

Palavras-chave: Manihot esculenta Crantz, legislação, farinha fermentada.

\section{Introdução}

A mandioca (Manihot esculenta Crantz), da família Euphorbiaceae, é conhecida por ser uma planta totalmente aproveitável, desde as raízes polposas às hastes e folhas. As raízes tuberosas são ricas em amido e prestam-se aos mais variados fins alimentícios e/ou industriais. De acordo com o IBGE (2007) estima-se que a quantidade de mandioca produzida no Brasil em 2007 foi de 26,5 milhões de toneladas, sendo o Pará o principal estado produtor com 5,2 milhões de toneladas, participando com aproximadamente $20 \%$ da produção nacional, seguido da Bahia, Paraná, Maranhão e Rio Grande do Sul.

A principal forma de aproveitamento das raízes é na produção de farinha de mesa e trata-se de atividade de grande importância social, pois abrange grande contingente da população rural, além de representar contribuição econômica significativa para os municípios paraenses, sendo de 34 $\mathrm{kg}$ o consumo per capita da farinha de mandioca na região metropolitana de Belém, o mais alto do 
Brasil e 2,3 vezes maior que o consumo da região metropolitana de Salvador, que é o segundo maior consumidor deste produto no país (Cardoso et al., 2001).

Embora a farinha constitua a forma mais ampla de aproveitamento industrial da mandioca, ainda não é um produto muito valorizado, sobretudo pela falta de uniformidade (Cereda et al., 2003). Segundo Lima (1982), a heterogeneidade da farinha de mandioca é devida principalmente à fabricação por pequenos produtores para seu próprio uso, cada um deles seguindo um processo próprio. Numa mesma propriedade é raro ocorrer uniformidade em fabricações sucessivas.

Chisté et al. (2007) cita que além das precárias condições higiênico-sanitárias das Casas de Farinha, as diferenças em seu processamento, tais como fermentação da mandioca, adição de corantes, intensidade da prensagem da massa triturada e temperatura do forno, influenciam no padrão de qualidade das farinhas, deixando-as fora do padrão exigido pela legislação vigente.

Segundo a Portaria $\mathrm{n}^{\mathrm{o}}$ 554, de 30.08.1995 do Ministério da Agricultura Pecuária e Abastecimento (MAPA) (Brasil, 1995), a farinha de mandioca d'água é o produto das raízes de mandioca sadias, devidamente limpas, maceradas, descascadas, trituradas (moídas), prensadas, desmembradas, peneiradas, secas à temperatura moderada, podendo novamente ser peneiradas ou não.

As raízes são fermentadas (maceradas) em água, raladas, prensadas e torradas. A fermentação é realizada em água parada ou corrente (igarapés) a qual confere às raízes características sensoriais peculiares. A ralação geralmente é feita em "caitutus" ou em "urupembas" (peneira grossa feita de palhas de palmeiras), a prensagem em "tipitis" (prensa artesanal feita de palha de buriti), ou prensas geralmente de fuso, e a torração em forno de barro aberto ou tachos de ferro (Sarmiento, 1993).

Sendo a farinha d'água um produto largamente consumido e difundido na cultura alimentar paraense, e devido grande parte da produção ser conduzida de modo artesanal nas chamadas Casas de Farinha, faz-se necessário conhecer e avaliar o padrão de qualidade da farinha de mandioca do grupo d'água, subgrupo fina, tipo 1, comercializadas nas principais feiras e supermercados da cidade de Belém, Pará.

\section{Material e Métodos}

\section{Amostras}

Dez amostras de $1 \mathrm{~kg}$, de diferentes lotes de farinha de mandioca do grupo d'água, subgrupo fina, tipo 1, foram coletadas nas principais feiras e supermercados da cidade de Belém, Pará, Brasil e em seguida encaminhadas para análise dos constituintes físico-químicos. 


\section{Caracterização físico-química}

- Teor de umidade - determinada por secagem direta em estufa a $105^{\circ} \mathrm{C}$ até peso constante, segundo método nº 920.151 da AOAC (1997);

- Atividade de água - A atividade de água foi medida diretamente em medidor portátil, modelo Pawkit, marca Decagon, após equilíbrio da amostra com o ambiente e na temperatura média de $25^{\circ} \mathrm{C}$;

- Teor de cinzas - as amostras foram carbonizadas até cessar a liberação de fumaça e, posteriormente, calcinadas em forno mufla a $550{ }^{\circ} \mathrm{C}$ até peso constante, segundo o método $\mathrm{n}^{\circ}$ 940.26 da AOAC (1997);

- Teor de lipídios - obtido por extração em Soxhlet, utilizando como solvente o éter de petróleo, arrastando os lipídios sob refluxo durante 4 horas e ao término com evaporação e recuperação do solvente, de acordo com o método nº 968.20 da AOAC (1997);

- Teor de proteínas - determinadas pela técnica micro-Kjeldahl e para conversão da porcentagem de nitrogênio em proteínas utilizou-se o fator 6,25, de acordo com o método $\mathrm{n}^{\circ} 920.152$ da AOAC (1997);

- Acidez total titulável - determinada através de titulação com $\mathrm{NaOH} 0,1 \mathrm{~N}$, sendo o pH da solução monitorada por potenciômetro. A amostra triturada é pesada e adicionada $100 \mathrm{~mL}$ de água destilada, agitando-se moderadamente. Em seguida a solução é titulada com $\mathrm{NaOH}$ rapidamente até pH 6. Após este ponto, é adicionado então, $\mathrm{NaOH}$ lentamente até pH 7. Após a obtenção do pH 7, a titulação é mantida adicionando 4 gotas de $\mathrm{NaOH}$ por vez, anotando o volume e valor de $\mathrm{pH}$ para cada adição. A seguir continuando a titulação $\geq 4$ gotas até próximo do $\mathrm{pH} 8,10( \pm 0,2)$ e encontrando o valor da titulação correspondente ao $\mathrm{pH} \mathrm{8,1} \mathrm{(por} \mathrm{interpolação),} \mathrm{sendo} \mathrm{o} \mathrm{resultado}$ expresso em miliequivalentes (meq) de $\mathrm{NaOH} / 100 \mathrm{~g}$, segundo método $\mathrm{n}^{\circ}$ 942.15B da AOAC (1997);

- Amido - determinado por digestão ácida em microondas, conforme a metodologia descrita por CEREDA et al. (2004);

\section{Análise estatística}

Os resultados médios obtidos em triplicata durante o estudo (média \pm desvio padrão) foram analisados com o auxílio do programa Statistica ${ }^{\circledR}$ versão 5.5 empregando a análise de variância (ANOVA) e Teste de Tukey $(\mathrm{p}<0,05)$. 


\section{Resultados e Discussão}

O conhecimento dos constituintes físico-químicos dos alimentos é de suma importância para a avaliação do potencial do produto a ser consumido ou matéria-prima a ser utilizada no preparo de alimentos, bem como para o conhecimento do valor nutricional da mesma.

De maneira geral, foram observadas (Tabela 1) variações significativas $(p<0,05)$ entre os constituintes das amostras analisadas. Algumas dessas variações são devido às características da própria matéria-prima, as raízes de mandioca.

Tabela 1 - Caracterização físico-química de amostras de farinha de mandioca do grupo d'água.

\begin{tabular}{cccccc}
\hline Amostras & $\begin{array}{c}\text { Umidade } \\
(\boldsymbol{\%})\end{array}$ & $\begin{array}{c}\text { Atividade de } \\
\text { água }\end{array}$ & $\begin{array}{c}\text { Cinzas } \\
(\boldsymbol{\%})\end{array}$ & $\begin{array}{c}\text { Proteínas } \\
(\%)\end{array}$ & $\begin{array}{c}\text { Lipídios } \\
(\%)\end{array}$ \\
\hline 1 & $4,13 \pm 0,06 \mathrm{~d}$ & $0,32 \pm 0,01 \mathrm{~d}$ & $0,22 \pm 0,04 \mathrm{e}$ & $0,78 \pm 0,08 \mathrm{~cd}$ & $0,54 \pm 0,08 \mathrm{bc}$ \\
2 & $2,81 \pm 0,19 \mathrm{e}$ & $0,18 \pm 0,00 \mathrm{~h}$ & $0,23 \pm 0,06 \mathrm{e}$ & $0,74 \pm 0,05 \mathrm{~d}$ & $0,65 \pm 0,05 \mathrm{~b}$ \\
3 & $4,03 \pm 0,16 \mathrm{~d}$ & $0,20 \pm 0,01 \mathrm{~g}$ & $0,16 \pm 0,02 \mathrm{e}$ & $0,70 \pm 0,03 \mathrm{~d}$ & $0,79 \pm 0,19 \mathrm{ab}$ \\
4 & $7,53 \pm 0,19 \mathrm{~b}$ & $0,40 \pm 0,01 \mathrm{c}$ & $0,79 \pm 0,04 \mathrm{~b}$ & $0,73 \pm 0,11 \mathrm{~d}$ & $0,74 \pm 0,03 \mathrm{ab}$ \\
5 & $4,61 \pm 0,06 \mathrm{c}$ & $0,29 \pm 0,00 \mathrm{e}$ & $0,60 \pm 0,01 \mathrm{c}$ & $1,09 \pm 0,13 \mathrm{~b}$ & $0,30 \pm 0,04 \mathrm{c}$ \\
6 & $7,52 \pm 0,02 \mathrm{~b}$ & $0,22 \pm 0,01 \mathrm{f}$ & $1,64 \pm 0,04 \mathrm{f}$ & $0,63 \pm 0,02 \mathrm{~d}$ & $0,59 \pm 0,07 \mathrm{bc}$ \\
7 & $8,19 \pm 0,08 \mathrm{a}$ & $0,51 \pm 0,00 \mathrm{a}$ & $0,94 \pm 0,05 \mathrm{a}$ & $0,64 \pm 0,01 \mathrm{~d}$ & $0,87 \pm 0,16 \mathrm{ab}$ \\
8 & $1,45 \pm 0,07 \mathrm{f}$ & $0,40 \pm 0,01 \mathrm{c}$ & $0,38 \pm 0,01 \mathrm{~d}$ & $0,58 \pm 0,00 \mathrm{~d}$ & $1,02 \pm 0,03 \mathrm{a}$ \\
9 & $4,54 \pm 0,04 \mathrm{c}$ & $0,19 \pm 0,01 \mathrm{gh}$ & $0,63 \pm 0,02 \mathrm{c}$ & $0,93 \pm 0,05 \mathrm{bc}$ & $0,63 \pm 0,01 \mathrm{~b}$ \\
10 & $8,39 \pm 0,16 \mathrm{a}$ & $0,43 \pm 0,00 \mathrm{e}$ & $0,74 \pm 0,05 \mathrm{~b}$ & $1,38 \pm 0,03 \mathrm{a}$ & $0,79 \pm 0,20 \mathrm{ab}$ \\
\hline
\end{tabular}

Os valores de uma mesma coluna, com a mesma letra, não diferem significativamente entre si (Teste de Tukey a $5 \%$ de significância). Média de três medições.

De acordo com a Tabela 1, com relação ao teor de umidade as amostras variaram de 1,45 a $8,39 \%$, sendo todas enquadradas dentro dos padrões exigidos pela atual legislação vigente (Brasil, 1995), que é no máximo de $13 \%$. O teor de umidade da farinha de mandioca está relacionado com o seu processo de fabricação podendo variar, principalmente com o tempo, temperatura de tostagem, o que não foi mensurado por fazer parte de um processo de fabricação artesanal, assim como as condições de armazenamento e material de embalagem. Chisté et al. (2006), Souza et al (2008a) e Souza et al. (2008b) obtiveram valores próximos para o teor de umidade após acompanhamento do processo de produção de farinha seca e Chisté et al. (2007) para farinha d'água, os valores também encontravam-se dentro do exigido pela legislação.

Considera-se a atividade de água igual a 0,60 como sendo o limite mínimo capaz de permitir o desenvolvimento de microrganismos, daí o fato dos alimentos desidratados, como a farinha de mandioca, serem considerados como microbiologicamente estáveis. Neste estudo, as amostras apresentaram atividade de água na faixa de 0,18 a 0,51. Tais resultados também são dependentes do processo de tostagem da farinha. Resultados semelhantes foram encontrados por Chisté et al. (2007) 
em farinha d'água $(0,30$ a 0,44) e Souza et al (2008a) em farinha seca $(0,09$ a 0,29). Chisté et al. (2006) ao avaliarem a qualidade da farinha seca comercializada na cidade de Belém, Pará, encontraram valores de até 0,61 de atividade de água.

O teor de cinzas (ou resíduo mineral fixo resultante da incineração da amostra do produto) da farinha de mandioca pode estar relacionado tanto com as características intrínsecas das raízes, quanto com o processo de fabricação, como, por exemplo, o descascamento. De acordo com Paiva (1991), valores maiores que a tolerância máxima permitida pode ser também um indicativo de teores significativos de $\mathrm{Ca}, \mathrm{P}, \mathrm{Fe}$ e $\mathrm{Mg}$, como também, mais provavelmente, indicam contaminação por material estranho ao produto ocasionado por falhas em algumas etapas do processamento. Com relação ao teor de cinzas (ou resíduo mineral fixo), a legislação exige no máximo 1,5\%, e as amostras neste estudo obtiveram percentuais na faixa de 0,16 a $0,94 \%$, estando apenas a amostra 6 acima do valor permitido.

Com relação a proteínas e lipídios, os percentuais obtidos foram de 0,58 a 1,38\% e 0,30 a $1,02 \%$, respectivamente. Chisté et al. (2007) consideram a farinha d'água como produto com baixos teores de proteínas e lipídios encontrando valores na faixa de 0,76 a 0,95\% de proteínas e 0,17 a 0,20\% de lipídios. Não há referências com relação aos teores de lipídeos na farinha de mandioca na legislação brasileira (Brasil, 1995). Contudo, sabe-se que tal característica pode variar devido às características intrínsecas das raízes da mandioca. Souza et al. (2008b) afirmam através da estimativa de contribuições relativas de cada característica da farinha que a variável proteína e lipídios apresentam importância de 4,3 e 5,7\% para a variabilidade das farinhas de mandioca comercializadas em alguns municípios do Acre.

Na produção artesanal das tradicionais Casas de Farinha, para fabricação da farinha d'água costuma-se utilizar parte da massa triturada do dia anterior, que não havia sido utilizada para finalização da produção da farinha no mesmo dia, adicionada à massa triturada após o processo de maceração da raiz de mandioca. Tal procedimento evita a perda de custo de matéria-prima não processada anteriormente. No entanto, essa falta de continuidade do processo, ou seja, iniciando-se o processo de fabricação da farinha, mas a batelada de massa triturada só é finalizada no dia posterior, faz com que as raízes de mandioca trituradas fiquem expostas à temperatura ambiente, ocorrendo fermentação e, conseqüente aumento de acidez do produto final, conforme visto na Tabela 2. Com relação a acidez, houve variação estatística significativa $(p<0,05)$ e $90 \%$ das amostras apresentaram-se acima do padrão exigido pela legislação que é de 3 meq NaOH/100 g, variando na faixa de 4,76 a 10,21 meq NaOH/100 g, e apenas a amostra 7 obteve percentual dentro dos padrões aceitos pela legislação. $\mathrm{O}$ aumento de acidez ocorre por dois motivos principais: pela fermentação das raízes de mandioca deixadas por um determinado período (geralmente 4 dias) submersas em água, e o outro pela concentração dos ácidos devido ao processo de torração. 
Portanto, o próprio processo de fabricação da farinha de mandioca do grupo d'água conduz a obtenção de produto com acidez superior ao da farinha de mandioca do grupo seca, devido a fermentação das raízes. No entanto, a legislação exige o mesmo valor no teor de acidez como parâmetro de qualidade do produto.

Tabela 2 - Acidez total e porcentagem de amido das farinhas de mandioca do grupo d'água.

\begin{tabular}{ccc}
\hline Amostras & $\begin{array}{c}\text { Acidez total titulável } \\
(\mathbf{m e q} \text { NaOH/ 100g) }\end{array}$ & $\begin{array}{c}\text { Amido } \\
(\%)\end{array}$ \\
\hline 1 & $9,52 \pm 0,12 \mathrm{~b}$ & $51,16 \pm 0,33 \mathrm{e}$ \\
2 & $8,07 \pm 0,10 \mathrm{~d}$ & $50,58 \pm 0,32 \mathrm{e}$ \\
3 & $8,02 \pm 0,09 \mathrm{~d}$ & $65,50 \pm 0,54 \mathrm{ab}$ \\
4 & $6,16 \pm 0,27 \mathrm{e}$ & $66,50 \pm 0,54 \mathrm{a}$ \\
6 & $8,46 \pm 0,25 \mathrm{~cd}$ & $66,53 \pm 0,44 \mathrm{a}$ \\
7 & $10,21 \pm 0,19 \mathrm{a}$ & $62,82 \pm 0,78 \mathrm{c}$ \\
8 & $2,63 \pm 0,17 \mathrm{~g}$ & $61,31 \pm 0,48 \mathrm{~d}$ \\
9 & $8,85 \pm 0,13 \mathrm{c}$ & $65,21 \pm 0,54 \mathrm{ab}$ \\
10 & $8,66 \pm 0,03 \mathrm{c}$ & $62,45 \pm 0,39 \mathrm{~cd}$ \\
\hline
\end{tabular}

Os valores de uma mesma coluna, com a mesma letra, não diferem significativamente entre si (Teste de Tukey a 5\% de significância). Média de três medições.

De acordo com Vilpoux (2003), a acidez da farinha permite obter informações sobre o processo de fermentação pelo qual passou o produto. Quanto maior a acidez, maior a intensidade da fermentação ou tempo do processo de pubagem (molho) das raízes. Chisté et al. (2007) também encontraram para farinha d'água valores acima do exigido pela legislação $(3,82$ a 8,25 meq $\mathrm{NaOH} / 100 \mathrm{~g})$.

Embora ocorra variação nos teores de amido entre as variedades de mandioca, o padrão exigido pela legislação é de $70 \%$. A variação do teor de amido observada nas amostras de farinha deste trabalho pode está relacionada com o seu processo de fabricação. Pois, em algumas "Casas de Farinha”, parte da massa triturada das raízes de mandioca é utilizada para a retirada de seu amido, retornando esta massa para o processamento, o que pode acarretar perda de amido no produto final (farinha).

Para a farinha de mandioca do grupo d'água, a Portaria $n^{\circ} 554$ de 30 de agosto de 1995 (Brasil, 1995) exige no mínimo 70\% de amido, e entre as dez amostras analisadas, todas possuíam percentual abaixo da tolerância mínima, variando na faixa de 50,58 a 66,53\% de amido. Chisté et al. (2007) encontraram valores de amido dentro do exigido para farinha d'água ao acompanhar o processamento nas casas de Farinha e obtiveram valores que variaram de 73,19 a 75,31\%. Souza et al. (2008b) afirmam através da estimativa de contribuições relativas que a variável carboidratos 
apresenta importância de 46,8\% para a variabilidade das farinhas de mandioca comercializadas em alguns municípios do Acre. No estado do Pará, a mandioca e a farinha como produto, são as principais fontes de carboidratos para uma significativa parcela da população de menor poder econômico, portanto é necessário garantir a qualidade deste parâmetro.

Segundo Vilpoux (2003), a produção artesanal de farinha d'água faz com que ela chegue ao consumidor com preço alto se comparado ao preço das farinhas produzidas nos outros estados do Nordeste, principalmente no sul do Brasil. As farinhas fabricadas no sul, principalmente Paraná, conseguem competir com preço inferior e qualidade mais padronizada apesar da grande diferença das farinhas locais. Esses fatores conduzem a uma mudança gradual das preferências do consumidor, com a tendência da farinha d'água perder cada vez mais mercado. Para que essa farinha de grande impacto cultural não desapareça, é importante identificar os pontos críticos onde perde competitividade para poder assim contorná-los.

\section{Conclusão}

Das dez amostras de farinha de mandioca analisadas, foram encontradas nove com valores acima do padrão permitido para a acidez total e apenas uma foi encontrada em acordo com a mesma, e todas as amostras apresentaram valores abaixo da tolerância mínima exigida para o amido, indicando assim a grande heterogeneidade da farinha d'água produzida e comercializada na cidade de Belém, Pará.

\section{Agradecimentos}

Ao CNPq e ao Fundo Estadual de Ciência e Tecnologia (FUNTEC) / Secretaria Executiva de Ciência, Tecnologia e Meio Ambiente (SECTAM), pelo apoio financeiro. À assistente de Pesquisa Solange Branches, da Embrapa Amazônia Oriental, pela ajuda e apoio em todos os momentos desta pesquisa.

\footnotetext{
Abstract

The aim of this work was to realize the physicochemical analysis in cassava flour from water group, thin, type 1, traded in the city of Belém, PA. According to the moisture, all the samples were on the standard demanded by the legislation, which is $13 \%$. The content of ash founded was from 0.16 to $0.94 \%$, and just one was above the maximum allowed by the legislation, which is $1.5 \%$. According to the total acidity, nine samples were above the legislation ( $3 \mathrm{meq} \mathrm{NaOH} / 100 \mathrm{~g}$ ) and just one showed the correct acidity. According to the starch, all the samples were below the minimum demanded by the legislation, which is $70 \%$. According to the proteins and lipids, the percentage gotten was from 0.58 to $1.38 \%$ and from 0.30 to $1.02 \%$, respectively. The water activity was from 0.18 to 0.51 , being considerate a microbiological stability product.
} 
Key-words: Manihot esculenta Crantz, legislation, fermented flour.

\section{Referências}

AOAC. Official methods of analysis of the Association of Official Analytical Chemists: edited Ig W. Horwitz $16^{\mathrm{a}}$ ed. Washington, V.2, 850p, 1997.

BRASIL, Portaria n. 554, de 30 de agosto de 1995. 1995. Norma de identidade, qualidade, apresentação, embalagem, armazenamento e transporte da farinha de mandioca. Diário Oficial da República Federativa do Brasil, Brasília, DF.

CARDoso, E. M. R.; MÜller, A. A.; SANTOS, A. I. M.; HOMMA, A. K. O.; ALVES, R. N. B. Processamento e Comercialização de Produtos Derivados de Mandioca no Nordeste Paraense. Embrapa Amazônia Oriental. Documento n. 102, 28p, Belém, PA, 2001.

CEREDA, M. P.; DAIUTO, E. R.; VILPOUX, O. Metodologia de Determinação de Amido por Digestão Ácida em Microondas. Revista ABAM, 29 p., 2004.

CEREDA, M. P.; VILPOUX, O. F.; TAKAHASHI, M. Balança hidrostática como forma de avaliação do teor de massa seca e amido. In: Cereda, M.P.; Vilpoux, O.F. Série Culturas de Tuberosas Amiláceas Latino Americanas, Vol. 3, Fundação Cargill, São Paulo, São Paulo, p. 30-46, 2003.

CHISTÉ, R. C.; COHEN, K. O.; MATHIAS, E. A.; RAMOA JUNIOR, A. G. A. Qualidade da farinha de mandioca do grupo seca. Ciência e Tecnologia de Alimentos, v. 26, n. 04, p.861-864, 2006.

CHISTÉ, R. C.; COHEN, K. O.; MATHIAS, E. A.; RAMOA JUNIOR, A. G. A. Estudo das propriedades físicoquímicas e microbiológicas no processamento da farinha de mandioca do grupo d'água. Ciência e Tecnologia de Alimentos, v. 27, p. 2, p.265-269, 2007.

IBGE. Produção Agrícola Municipal: Culturas temporárias e permanentes, Rio de Janeiro, v.34, p.1-69, 2007.

LIMA, U. A. Manual técnico de beneficiamento e industrialização da mandioca. São Paulo: Secretaria de Ciência e Tecnologia, 56 p. (Programa Adequação), 1982.

PAIVA, F. F. A. Controle de qualidade da farinha de mandioca (Manihot esculenta Crantz) produzida na região metropolitana de Fortaleza. Dissertação de Mestrado, Universidade Federal do Ceará, Fortaleza, CE. 216 p, 1991.

SARMIENTO, F. M. Z. Utilização de farinha de macaxeira (Manihot esculenta Crantz) obtida pelo método HEIM em panificação. Dissertação de Mestrado, Universidade Federal do Ceará, Fortaleza, CE. 71p., 1993.

SOUZA, J. M. L.; ÁlVARES, V. S.; LEITE, F. M. N.; REIS, F. S.; FELISBERTO, F. A. V. Caracterização físicoquimica de farinhas oriundas de variedades de mandioca utilizadas no vale do Juruá, Acre. Acta Amazônica, v. 38, n. 4, p.761-766. 2008a.

SOUZA, J. M. L.; NEGREIROS, J. R. S.; ÁlvARES, V. S.; LEITE, F. M. N.; SOUZA, M. L.; REIS, F. S.; FELISBERTO, F. A. V. Variabilidade físico-química da farinha de mandioca. Ciência e Tecnologia de Alimentos, v. 28, n. 4, p.907-912, 2008b.

VILPOUX, O. F. Produção de farinha d'água no Estado do Maranhão. In: CEREDA, M. P; VILPOUX, O. F. Série Culturas de Tuberosas Amiláceas Latino Americanas, Vol. 3. Fundação Cargill, São Paulo, São Paulo, p. 621-642, 2003.

\section{Dados Dos autores:}

Nome completo: Renan Campos Chisté.

Filiação institucional: Universidade Estadual de Campinas - UNICAMP.

Departamento: Departamento de Ciência de Alimentos - DCA.

Função ou cargo ocupado: Doutorando em Ciência de Alimentos.

Endereço: Universidade Estadual de Campinas, Faculdade de Engenharia de Alimentos, 
Departamento de Ciências de Alimentos. FEA/DCA/ Caixa Postal 6121.

Telefone para contato: (19) 35212159

e-mail:renanchiste@gmail.com

Nome completo: Kelly de Oliveira Cohen.

Filiação institucional: Embrapa Cerrados.

Função ou cargo ocupado: Pesquisador III.

Endereço: BR 020 km 18, Planaltina-DF, Brasil. CEP:73310-970. Caixa Postal: 08223.

Telefones para contato: Fone: (61) 3388-9898 - Fax: (61) 3388-9879

e-mail: kelly.cohen@cpac.embrapa.br 